\title{
Enumeration of clostridia in goat milk using an optimized membrane filtration technique
}

\author{
Anita Reindl, ${ }^{\dagger} \dagger$ Monika Dzieciol, ${ }^{*}$ Ingeborg Hein, ${ }^{*}$ Martin Wagner, ${ }^{*}$ and Peter Zangerl† ${ }^{1}$ \\ *Institute for Milk Hygiene, Department for Farm Animals and Veterinary Public Health, Veterinärplatz 1, 1210 Vienna, Austria \\ †Federal Institute for Alpine Dairying, Rotholz 50A, 6200 Jenbach, Austria
}

\section{ABSTRACT}

A membrane filtration technique developed for counting butyric acid bacteria in cow milk was further developed for analysis of goat milk. Reduction of the sample volume, prolongation of incubation time after addition of proteolytic enzyme and detergent, and a novel step of ultrasonic treatment during incubation allowed filtration of goat milk even in the case of somatic cell counts (SCC) exceeding $10^{6} / \mathrm{mL}$. However, filterability was impaired in milk from goats in late lactation. In total, spore counts were assessed in 329 farm bulk goat milk samples. Membrane filtration technique counts were lower than numbers revealed by the classic most probable number technique. Thus, method-specific thresholds for milk to evaluate the risk of late blowing have to be set. As expected, the spore counts of milk samples from suppliers not feeding silage were significantly lower than the spore counts of milk samples from suppliers using silage feeds. Not only were counts different, the clostridial spore population also varied significantly. By using 16S rRNA gene PCR and gene sequencing, 342 strains from 15 clostridial species were identified. The most common Clostridium species were Clostridium tyrobutyricum (40.4\%), Clostridium sporogenes (38.3\%), Clostridium bifermentans (7.6\%), and Clostridium perfringens (5.3\%). The 2 most frequently occurring species $C$. tyrobutyricum and $C$. sporogenes accounted for $84.7 \%$ of the isolates derived from samples of suppliers feeding silage $(\mathrm{n}=288)$. In contrast, in samples from suppliers without silage feeding $(\mathrm{n}=55)$, these species were detected in only $45.5 \%$ of the isolates.

Key words: clostridia, butyric acid bacteria, goat milk, membrane filtration, PCR

Received April 9, 2014.

Accepted July 3, 2014.

${ }^{1}$ Corresponding author: peter.zangerl@rotholz.lebensministerium.at

\section{INTRODUCTION}

Clostridium is a diverse genus of obligate anaerobic, endospore-forming, and gram-positive microorganisms. Pathogenic species such as Clostridium botulinum, Clostridium difficile, Clostridium tetani, and Clostridium perfringens produce up to $18 \%$ of all known bacterial toxins, thus making Clostridium the most toxic prokaryotic genus and a significant concern to human and animal health (Popoff and Stiles, 2005). However, the food-related pathogens C. botulinum and C. perfringens are of negligible importance to the dairy industry. Two outbreaks of botulism related to Brie cheese (Sébald et al., 1974; Johnson et al., 1990) and Mascarpone cheese (Aureli et al., 1996, 2000) were associated with elevated $\mathrm{pH}$ values in the product and temperature abuse. Botulism from hazelnut yogurt was traced to toxin contained in nut purée but not in the milk component (O'Mahony et al., 1990).

Nevertheless, spores of clostridia are a challenge for the dairy industry as major spoilage organisms of hard and semi-hard cheeses. A serious defect predominantly in Emmental cheese is the formation of white putrid spots in the interior of the cheese caused by intense proteolysis by Clostridium sporogenes (Hüfner, 2001; Bachmann et al., 2011). Clostridium oceanicum and $C$. sporogenes may also provoke proteolysis on the surface of film-matured cheeses, causing white taints on the cheese surface accompanied by an intense putrid odor (Hüfner, 2001). The most important defect, however, is butyric acid fermentation (BAF) by Clostridium tyrobutyricum, which converts lactic acid to butyric acid, acetic acid, $\mathrm{CO}_{2}$, and hydrogen. This defect causes formation of cracks, abnormally shaped or excessively big eyes, or even blowing of the cheese, accompanied by off-flavors after several weeks or months of ripening. Thus, the defect is referred to as "late blowing." Other clostridia (e.g., Clostridium beijerinckii, C. sporogenes, Clostridium butyricum, and Clostridium bifermentans) were also detected in defective cheeses, but they are considered as enhancers of the late-blowing defect (Klijn et al., 1995; Le Bourhis et al., 2007; Daly et al., 2010). However, all these species as well as Clostridium 
cochlearium may spoil processed cheese products that have been gently heated (Stadhouders et al., 1985; Lycken and Borch, 2006) because the surviving spores are able to germinate and grow due to the presence of lactose and the relatively high $\mathrm{pH}$ values of 5.5 to 6.0 .

The main source of clostridial spores in raw milk is silages of insufficient microbial quality. The spores are concentrated in the feces of the lactating animals and enter the milk during milking, especially when improper hygiene practices fail to minimize the spores present on the teat surfaces (Stadhouders et al., 1985; Vissers et al., 2007; Sheehan, 2011).

Preventive measures to control BAF are (1) avoiding milk contamination by prohibiting use of silage as a feed for lactating ruminants, which is practiced in some European regions for the manufacture of cooked hard cheeses; (2) ensuring good hygiene practices in animal husbandry and during the milking process; (3) removing spores from cheese milk through bactofugation or microfiltration; and (4) using clostridial growth inhibitors such as nitrate or lysozyme (Stadhouders et al., 1985; Bachmann, 1995; Sheehan, 2011).

In recent years, cheeses produced from goat milk are of increasing commercial relevance, and the lateblowing defect was also observed in these cheeses even when processing milk from farms without silage feeding. However, data of the clostridial load in goat milk have not been available until now.

Control of BAF in cheese needs reliable methods to enumerate the relevant clostridial spores in farm bulk milk or in cheese milk before processing. Thus, methods must be available for counting lactate fermenting butyric acid bacteria (BAB), essentially $C$. tyrobutyricum. As few as 10 to several hundred spores of BAB per liter of milk may induce BAF (Freyer and Halligan, 1976; Bergère and Sivelä, 1990; Sheehan, 2011). Therefore, most probable number (MPN) techniques are used including the possibility of detecting the spores in up to 10-mL sample volumes. For milk of cows fed a silage-free diet, a threshold of 200 BAB spores per liter is recommended (Freyer and Halligan, 1976; Teuber, 1985). Unfortunately, neither an international standard method exists nor any routine method is able to count specifically the relevant species $C$. tyrobutyricum (Zangerl, 1989; Bergère and Sivelä, 1990).

The methods differ in the choice of enrichment broths, pasteurization conditions of milk samples to eliminate the vegetative cells, and incubation times. The most important means to achieve sufficient selectivity for $\mathrm{BAB}$ are the presence of lactate as available carbon source and adjustment of $\mathrm{pH}$ of the broth to levels prevalent in hard and semi-hard cheeses ( $\mathrm{pH} 5.4-5.5$ ). In the Netherlands and in Austria, a milk medium containing glucose and lactate adjusted to $\mathrm{pH} 5.45$ is used [NIZO method (NIZO food research BV, Ede, the Netherlands) according to van den Berg et al. (1988)]. Recently, this method was laid down as the national standard in the Netherlands in a slightly modified way (NEN, 2009). In Germany, reinforced clostridial medium (RCM) adjusted with lactic acid to $\mathrm{pH} 5.4$ is used (VDLUFA, 1996). France and Switzerland prefer a modified Bryant and Burkey broth containing lactate as the sole fermentable carbon source (CNERNA, 1986; Jakob, 2011). Depending on the method, the pasteurization conditions vary between 75 and $80^{\circ} \mathrm{C}$ for 5 to 10 min, and incubation times vary between 3 and $7 \mathrm{~d}$ at $37^{\circ} \mathrm{C}$. Anaerobiosis is achieved by sealing the tubes with paraffin or water agar. The formation of gas, which lifts the paraffin or agar plug, serves as the diagnostic system.

A membrane filtration technique (MFT) was developed by Bourgeois et al. (1984) as an alternative to the time- and material-consuming and cumbersome MPN methods. The MFT was modified by Agroscope (Bern, Switzerland). According to Agroscope instructions (unpublished), a $40-\mathrm{mL}$ sample of milk is pasteurized at $76^{\circ} \mathrm{C}$ for $15 \mathrm{~min}$, incubated with $5 \mathrm{~mL}$ of trypsin solution $(2 \%$ in Tris- $\mathrm{HCl})$ and $2.5 \mathrm{~mL}$ of Triton X-100 $\left(16 \%\right.$ solution) in a water bath for 15 min at $55^{\circ} \mathrm{C}$ and filtrated under $250 \mathrm{kPa}$ of pressure through a membrane filter with a pore size of $0.8 \mu \mathrm{m}$. The filter is transferred onto a modified reinforced clostridial agar (RCAm) containing D-cycloserine to inhibit the growth of facultative anaerobic bacilli (Abgrall and Bourgeois, 1985; Jonsson, 1990) and acid fuchsin dye, supporting the differentiation of colonies (Bergère and Sivelä, 1990; Jakob, 2011). Bächli (1997) mentions a modification by M. Casey and J. Gruskovnjak (unpublished internal report; Agroscope, Bern, Switzerland, 1995) through introducing calcium chloride-2-hydrate, which should enhance germination of $C$. tyrobutyricum spores. Colonies are counted after anaerobic incubation at $37^{\circ} \mathrm{C}$ for $72 \mathrm{~h}$. Typical C. tyrobutyricum colonies are pink to dark red, convex, round, and not fimbriated, with a diameter of 1 to $3 \mathrm{~mm}$. However, when applying this method to goat milk, problems occur with filterability, probably because of the physiologically high SCC (J. Hummerjohann, Agroscope, Bern, Switzerland, personal communication).

Therefore, the aim of the current study was to optimize the MFT for analyzing goat milk. For method validation, the MFT was compared with the NIZO method (van den Berg et al., 1988) both in cow and goat milk samples. The modified procedure was then used on bulk raw milk collected from farmers to assess the BAB spore counts when using silage and nonsilage feeds. Finally, to study the composition of the clostridia population, isolates were typed by partial $16 \mathrm{~S}$ rRNA 
gene amplification (Pille et al., 2004) and sequencing analysis.

\section{MATERIALS AND METHODS}

\section{Adaptation of the Filtration Procedure for Goat Milk}

To find the most appropriate filtration procedure for goat milk, various modifications were tested: (1) an increase in trypsin concentration (from 2 to 10 and 15\%; catalog no. 215240; Difco; Becton Dickinson, Sparks, MD), (2) an increase of Triton X-100 concentration [from 16 to $32 \%$ (vol/vol); model 1.08603; Merck KGaA, Darmstadt, Germany], (3) replacement of trypsin by subtilisin [ 1 and $2 \%$ (vol/vol) solution; product P54595G; Sigma-Aldrich Chemie GmbH, Munich, Germany], and (4) substitution of Triton X-100 by Tween 80 [1\% (vol/vol) solution; product 93781; Fluka, Vienna, Austria].

Furthermore, the effect of a prolongation of the incubation time (30 min instead of $15 \mathrm{~min}$ ), the incubation temperature $\left(38^{\circ} \mathrm{C}\right.$ instead of $\left.55^{\circ} \mathrm{C}\right)$, and the use of an ultrasonic treatment (Sonorex Digital DK102P ultrasonic bath; Bandelin Electronic GmbH, Berlin, Germany) were assessed.

\section{Validation of the MFT}

The MFT was validated on the basis of the following 4 criteria.

Productivity of $\mathbf{R C A m}$. The productivity of RCAm was assessed according to the European Committee for Standardization guidelines (CEN, 2011). The productivity ratio $\left(\boldsymbol{P}_{\boldsymbol{R}}\right)$ of the target microorganisms on a selective medium was calculated using the equation $P_{R}=$ $N_{S} / N_{O}$, with $N_{S}$ being the total colony count obtained on the tested medium (RCAm), and $N_{O}$ being the total colony count obtained on blood agar containing $5 \%$ sheep blood (COS agar; product 43041; bioMérieux SA, Marcy-l'Étoile, France) as reference culture medium. The calculated value of the target microorganisms on a selective medium should be at least 0.1 (CEN, 2011). For this approach, the reference strains $(C$. sporogenes DSM 795, C. sporogenes DSM 633, C. tyrobutyricum DSM 663, and C. butyricum DSM 10702) and a laboratory strain [C. sporogenes internal number (IN) 1183] were used. The strains were activated by anaerobic incubation in RCM (Merck KGaA; model 1.05411) for $24 \mathrm{~h}$ at $37^{\circ} \mathrm{C}$.

Comparison of MFT Spore Counts to Standard Plate Spore Counts Using Reference Cultures. Spore counts of the reference cultures $C$. tyrobutyricum DSM 663, C. sporogenes DSM 795, C. butyricum DSM 10702, and C. perfringens DSM 756 were determined after anaerobic incubation in RCM supplemented with $\mathrm{MnSO}_{4}(50 \mathrm{mg} / \mathrm{L}), \mathrm{CaCl}_{2} \times 2 \mathrm{H}_{2} \mathrm{O}$ $(100 \mathrm{mg} / \mathrm{L})$ and $\mathrm{MgSO}_{4}(50 \mathrm{mg} / \mathrm{L})$ for $24 \mathrm{~h}$ at $37^{\circ} \mathrm{C}$. After incubation, the cultures were diluted 1:10 with one-quarter-strength Ringer solution (Merck KGaA; model 1.15525) and heated in a $76^{\circ} \mathrm{C}$ water bath for 20 min. Standard plate counts of the working cultures were determined by surface plating (anaerobic incubation on RCAm for $72 \mathrm{~h}$ at $37^{\circ} \mathrm{C} ; 2$ plates per dilution). The MFT spore counts were determined after appropriate dilution of the pasteurized reference culture with one-quarter-strength Ringer solution. Ten milliliters of diluted culture was dispersed in $90 \mathrm{~mL}$ of low-fat UHT milk and $20 \mathrm{~mL}$ of that mixture was prepared for filtration using the prolonged incubation time of $30 \mathrm{~min}$ in a water bath at $55^{\circ} \mathrm{C}$. All experiments were performed in duplicate.

Effect of Sonication on Recovery of Spores From a Reference Material. The influence of the ultrasonic treatment was evaluated by comparing the spore counts of a reference material provided by Agroscope (silage slurry; reference value $90 \pm 40$ spores/L). Ten subsamples were incubated in a water bath and 10 subsamples in the ultrasonic water bath (40-mL sample volume and incubation $55^{\circ} \mathrm{C}$ for $30 \mathrm{~min}$ ). Further, appropriate dilutions of the reference cultures were pasteurized as described above. Samples of $40-\mathrm{mL}$ volume were incubated after addition of trypsin and Triton $\mathrm{X}-100$ for $30 \mathrm{~min}$ at $55^{\circ} \mathrm{C}$ in a water and ultrasonic water bath, respectively. Spore counts were assessed by surface plating on RCA, using 2 plates per dilution (anaerobic incubation for $72 \mathrm{~h}$ at $37^{\circ} \mathrm{C}$ ).

Comparison of the MFT and MPN Technique. To compare the spore counts obtained by the MFT and the MPN technique, the NIZO method according to van den Berg et al. (1988) for the detection of BAB spores was used. The performance was assessed using 47 naturally contaminated raw milk samples (21 cow milk samples and 26 goat milk samples). The MPN counts were determined by analysis of $3 \times 10-, 3 \times$ $1-$, and $3 \times 0.1-\mathrm{mL}$ sample volumes using pasteurization conditions of $80^{\circ} \mathrm{C}$ for $5 \mathrm{~min}$ and incubation of the tubes at $37^{\circ} \mathrm{C}$ for $4 \mathrm{~d}$. Cow milk samples were analyzed according to the Agroscope protocol (see Introduction). For goat milk samples, the modified filtration procedure was used.

\section{Raw Goat Milk Samples}

In total, 329 raw goat milk samples were analyzed. Two hundred fourteen farm bulk milk samples from 127 suppliers (144 samples with silage feeding and 70 samples without silage feeding) in Austria and Bavaria (Germany) were collected from May 2009 to October 
2009. The samples $(\sim 40 \mathrm{~mL}$ each) were transferred to the Federal Institute for Alpine Dairying (BAM) Rotholz (Jenbach, Austria), either refrigerated on the day of sampling or after a maximum of $3 \mathrm{~d}$ of storage at $-20^{\circ} \mathrm{C}$. Before analysis, the samples were stored for a maximum of $14 \mathrm{~d}$ and were defrosted in a $25^{\circ} \mathrm{C}$ water bath, unless analysis was performed within $24 \mathrm{~h}$ after sampling. To assess seasonal variations of the spore counts, a further 115 bulk milk samples $(150 \mathrm{~mL}$ each $)$ from 5 suppliers not feeding silage were collected every 2 wk from May 2009 until April 2010.

\section{Analysis of Goat Milk Samples}

Membrane Colony Count Method. Twenty milliliters of raw goat milk was pasteurized in a $76^{\circ} \mathrm{C}$ water bath for $20 \mathrm{~min}$. After cooling down to $55^{\circ} \mathrm{C}$ in a water bath, $5 \mathrm{~mL}$ of trypsin [Difco; $2 \%$ (wt/vol), dissolved in $0.1 M$ Tris- $\mathrm{HCl}$, sterile filtrated $(\mathrm{pH} 7.8)]$ and $2.5 \mathrm{~mL}$ of sterile Triton X-100 [16\% (vol/vol); model 1.08603; Merck $\mathrm{KGaA}$ ] were added, which was followed by an incubation at $55^{\circ} \mathrm{C}$ for $30 \mathrm{~min}$ in a standard ultrasonic bath. Afterward the samples were filtrated in a filtration apparatus (Jenzer, Cressier, Switzerland) through a $47-\mathrm{mm}$ nitrocellulose membrane filter $(0.8-\mu \mathrm{m}$ pore size; AAWP047SO; Millipore Corp., Billerica, MA) by applying a pressure of $250 \mathrm{kPa}$. The filter was transferred onto an RCAm containing $50.0 \mathrm{~g}$ of RCA (model 1.05410; Merck KGaA), $3.0 \mathrm{~g}$ of calcium chloride2-hydrate (model 1.02382; Merck KGaA), $2.0 \mathrm{~g}$ of acid fuchsin (model 1.05231; Merck KGaA), and $0.2 \mathrm{~g}$ of D-cycloserine (product 42619; bioMérieux SA) per liter and incubated under anaerobic conditions at $37^{\circ} \mathrm{C}$ for $72 \mathrm{~h}$.

After incubation, all pink-to-purple colonies were counted and the color and the appearance of the colonies were documented. For PCR confirmation, up to 5 colonies were chosen from each plate and streaked on COS agar (product 43041; bioMérieux SA). After anaerobic incubation at $37^{\circ} \mathrm{C}$ for $72 \mathrm{~h}$, the isolates were subcultured in RCM (model 1.05411; Merck KGaA) anaerobically at $37^{\circ} \mathrm{C}$ for $24 \mathrm{~h}$. One thousand two hundred microliters of the cultured broth supplemented with $400 \mu \mathrm{L}$ of glycerol (Merck KGaA) and $200 \mu \mathrm{L}$ of defibrinated horse blood (Oxoid Ltd., Basingstoke, UK) were stored at $-40^{\circ} \mathrm{C}$ (Nunc CryoTube; Sigma-Aldrich Chemie $\mathrm{GmbH}$ ) until analysis.

In the case of clogged filters, the spore count was determined by the MPN technique (NIZO method according to van den Berg et al., 1988). The isolates were obtained by streaking a loop of incubated medium of a gas-positive tube onto COS agar (product 43041; bioMérieux SA).
$\boldsymbol{S C C}$. Somatic cell counts were determined in milk samples used in the preliminary experiments to optimize the MFT and in the 115 bulk milk samples tested during the 1-yr period. Somatic cell counting was performed using a Fossomatic 5000 (Foss Electric A/S, Hillerød, Denmark) according to the manufacturer's instructions and the guidelines of Agrarmarkt Austria (AMA, 2013).

\section{DNA Isolation}

Cultures were prepared in RCM and were incubated anaerobically at $37^{\circ} \mathrm{C}$ for $24 \mathrm{~h}$. For the DNA isolation, $1 \mathrm{~mL}$ of an overnight culture was centrifuged at 8,000 $\times g$ for 5 min at ambient temperature. The pellet was processed with the commercial NucleoSpin tissue kit (Macherey-Nagel, Vienna, Austria), using the support protocol for gram-positive bacteria according to the manufacturer's instructions. The DNA concentration was determined fluorometrically using a Hoefer DyNa Quant 200 fluorometer (Pharmacia Biotech, San Francisco, CA), and DNA was diluted to $0.1 \mathrm{ng} / \mu \mathrm{L}$ in diethylpyrocarbonate (DEPC)-treated water (Fermentas GmbH, St. Leon-Rot, Germany) and stored at $-20^{\circ} \mathrm{C}$.

\section{PCR Amplification of 16S rRNA Gene and Sequencing}

The sequences of primers used in this study are listed in Table 1 and were synthesized by Eurofins Genomics (Ebersberg, Germany). The 16S rRNA gene-specific oligonucleotides were used to amplify a 525-bp fragment spanning the V1, V2, and V3 regions (Pille et al., 2004; Table 1). The amplification of the $16 \mathrm{~S}$ rRNA gene was carried out in a total volume of $50 \mu \mathrm{L}$ containing $20 \mathrm{mmol}$ of Tris- $\mathrm{HCl} / \mathrm{L} ; 50 \mathrm{mmol}$ of $\mathrm{KCl} / \mathrm{L} ; 1.5 \mathrm{mmol}$ of $\mathrm{MgCl}_{2} / \mathrm{L} ; 200 \mathrm{nmol} / \mathrm{L}$ of each primer $(16 \mathrm{~S} 8-27 \mathrm{~F}$ and B-16S509-525R); $200 \mathrm{mM}$ concentrations (each) of deoxyadenosine triphosphate (dATP), deoxythymidine triphosphate (dTTP), deoxyguanosine triphosphate (dGTP), and deoxycytidine triphosphate (dCTP); 1.5 U of Platinum Taq DNA polymerase (Invitrogen, Vienna, Austria); and $10 \mu \mathrm{L}$ of template DNA. Amplification was performed in a thermocycler (Gene Amp PCR system 9700) following initial denaturation for 2 min at $94^{\circ} \mathrm{C}$, in 25 cycles of $94^{\circ} \mathrm{C}$ for $30 \mathrm{~s}, 55^{\circ} \mathrm{C}$ for $30 \mathrm{~s}$, $72^{\circ} \mathrm{C}$ for $1 \mathrm{~min}$, with a final extension at $72^{\circ} \mathrm{C}$ for $4 \mathrm{~min}$. The amplified product was visualized by transillumination after electrophoresis in a 1.5\% Tris-borate-EDTA (TBE) agarose gel.

The amplified PCR products were sequenced in both directions (Macrogen Inc., Seoul, Korea). Sequence 
Table 1. Sequences of primers used in this study

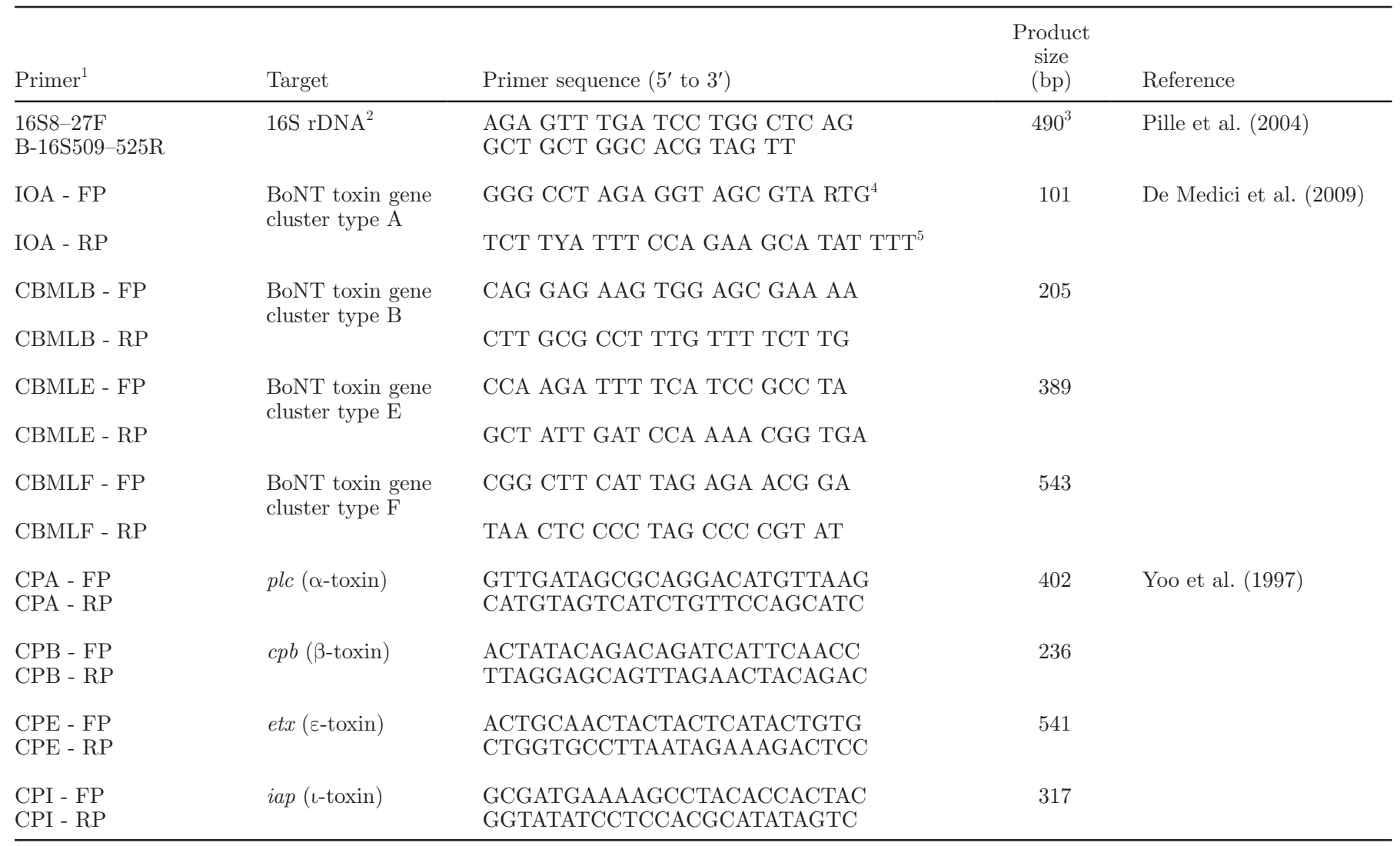

${ }^{1}$ Primers were synthesized by Eurofins (Ebersberg, Germany). $\mathrm{F}$ and $\mathrm{FP}=$ forward primer; $\mathrm{R}$ and $\mathrm{RP}=$ reverse primer.

${ }^{2} \mathrm{rDNA}=$ ribosomal DNA.

${ }^{3}$ Clostridium butyricum DSM 2478 (GenBank accession number X68177; http://blast.ncbi.nlm.nih.gov/Blast.cgi).

${ }^{4} \mathrm{R}=\mathrm{C}$ or $\mathrm{T}$.

${ }^{5} \mathrm{Y}=\mathrm{A}$ or $\mathrm{G}$.

pairs (each derived from the respective forward and reverse primer) were aligned using the MultAlin web server (Corpet, 1988). For species identification, sequences were compared with the GenBank database using the BLAST similarity search program (http:// blast.ncbi.nlm.nih.gov/Blast.cgi). The sequence data for the clones, which were not in the GenBank database, have been submitted to this database (accession numbers HQ291785 and HQ291786).

In $C$. sporogenes and $C$. botulinum, the amplified region of the $16 \mathrm{~S}$ rRNA gene is identical. Thus, a multiplex PCR for identification of C. botulinum toxins (types A, B, E, and F) was used for further differentiation (De Medici et al., 2009; Table 1).

The potential for toxin production of all C. perfringens isolates was tested by PCR targeting $\alpha$ - (produced by all toxin types), $\beta$ - (produced by toxin types $\mathrm{B}$ and C), $\varepsilon$ - (produced by B and D), and ı-toxins (produced by toxin type E; Yoo et al., 1997; Table 1).

\section{Statistical Analysis}

All tests were carried out after logarithmic transformation of the data. Depending on the sample material, mean value comparisons were made with the Student's $t$-test for unpaired or paired samples.

\section{RESULTS}

\section{Adaptation of the Filtration Procedure for Goat Milk}

Preliminary experiments showed that filterability of the milk was dependent on the SCC (data not shown). Alteration of trypsin and Triton X-100 concentrations, the use of Tween 80, modified incubation temperature, and the use of subtilisin did not enhance filterability of the milk. The highest filterability was achieved by using an ultrasonic treatment for 30 min after addition of trypsin (2\%, wt/vol) and Triton X-100 solution (16\%, $\mathrm{vol} / \mathrm{vol}$ ) and by a reduction of the filtrated milk volume 
Table 2. Productivity of modified reinforced clostridial agar (RCAm)

\begin{tabular}{llcc}
\hline Organism & Strain & $\mathrm{P}_{\mathrm{R}} \min -\mathrm{P}_{\mathrm{R}} \max ^{1}$ & $\begin{array}{c}\text { No. of } \mathrm{P}_{\mathrm{R}} \geq 0.1 / \\
\text { total no. }\end{array}$ \\
\hline Clostridium tyrobutyricum & DSM 663 & $0.6-2.7$ & $6 / 6$ \\
Clostridium butyricum & DSM 10702 & $<0.1-1.5$ & $2 / 4$ \\
Clostridium perfringens & DSM 756 & $<0.1-0.2$ & $2 / 7$ \\
Clostridium sporogenes & DSM 795 & $<0.1$ & $0 / 6$ \\
Clostridium sporogenes & DSM 633 & 0.2 & $1 / 1$ \\
Clostridium sporogenes & IN 1186 & $0.2-0.4$ & $4 / 4$ \\
${ }^{1} \mathrm{P}_{\mathrm{R}}=$ productivity ratio; min = minimum; max = maximum. & & \\
${ }^{2}$ Number of trials with $\mathrm{P}_{\mathrm{R}} \geq 0.1 /$ total number of trials. & &
\end{tabular}

from 40 to $20 \mathrm{~mL}$. The modifications allowed filtration of milk even when high somatic cell counts of $>10^{6}$ cells $/ \mathrm{mL}$ were present.

\section{Validation of the MFT}

Productivity of RCAm. Results of the $P_{R}$ of RCAm are listed in Table 2. For C. tyrobutyricum DSM 663 , the medium showed excellent recovery (mean $P_{R}=$ 1.23). For C. butyricum DSM 10702 and C. perfringens DSM 756, a $P_{R} \geq 0.1$ was obtained in 2 out of 4 and 7 independent trials, respectively. Of the 3 C. sporogenes strains (DSM 795, DSM 633, and IN 1183) straindependent growth differences were observed. Whereas the C. sporogenes strain DSM 795 showed insufficient growth on RCAm in 6 trials, a $P_{R} \geq 0.1$ for $C$. sporogenes DSM 633 and IN 1186 strains was achieved in all experiments.

Comparison of MFT Spore Counts with Standard Plate Spore Counts Using Reference Cultures. Spore counts of the reference cultures $C$. tyrobutyricum DSM 663, C. sporogenes DSM 795, and C. butyricum DSM 10702 were derived by the SPC procedure and the MFT $(20-\mathrm{mL}$ sample volume and 30-min incubation). Both methods yielded similar results and detected $5.4 \log _{10} \mathrm{cfu} / \mathrm{mL}(\mathrm{SD} \pm 1.2)$ and $5.3 \log _{10} \mathrm{cfu} / \mathrm{mL}(\mathrm{SD} \pm 1.1)$, respectively $(\mathrm{n}=7)$. No significant differences for both methods were observed $(P>0.05)$. Results of $C$. perfringens are not included because no spores could be detected in $0.1 \mathrm{~mL}$ of working culture.

Effect of Sonication. The influence of the ultrasonic treatment on spore viability was assessed by analysis of 10 subsamples of reference material incubated in a water bath or ultrasonic bath. Arithmetic means of reference material samples with and without sonication treatment were 168 and 143 spores/L, respectively, and did not differ significantly $(P>0.05)$. Spore counts of the reference cultures C. tyrobutyricum DSM 663, C. butyricum DSM 10702, and C. sporogenes DSM 633 derived from pretreatment with and without sonication yielded results on the same order of magnitude (data not shown). Again, C. perfringens is not included due to the lack of spores in the working culture.

Comparison of the MFT and MPN Technique. Out of 47 goat and cow milk samples, 30 (63.8\%) tested positive by the MPN procedure and $25(53.2 \%)$ by the MFT. The limit of detection equaled 30 spores/L for the MPN technique and 50 spores/L of goat milk for the MFT. In the case of cow milk, the limit of detection equaled 25 spores/L due to the higher sample volume $(40 \mathrm{~mL})$.

In cases where spore counts were obtained by both methods (21 samples), significant differences in counts were detected $(P<0.01)$. On average, the spore counts obtained by the MFT were $40 \%$ lower than obtained by the MPN technique (geometric mean $=120 \mathrm{MPN} / \mathrm{L}$ vs. $73 \mathrm{cfu} / \mathrm{L})$.

\section{Spore Counts of Farm Bulk Milk}

As expected, the spore counts of raw milk from suppliers not feeding silage were significantly lower than the spore counts of milk from farms feeding silage (Table 3). Out of 144 milk samples derived from farms with silage feeding, 20 samples $(13.9 \%)$ exceeded spore counts of $1,000 \mathrm{cfu} / \mathrm{L}$ (maximum $=5,000$ spores $/ \mathrm{L}$ ). In contrast, the maximum spore count for milk samples from suppliers without silage feeding $(\mathrm{n}=70)$ was 300 spores/L. As shown in Table 3, clostridial spores were not detected in the majority of the samples derived from suppliers not feeding silage $(75.7 \%)$.

To study seasonal aspects, 115 farm bulk milk samples from 5 suppliers without silage feeding were repeatedly analyzed during a 1-yr period. It was observed that filterability of goat milk was impaired in December to March samples even when applying the modified filtration procedure. In these cases, the MPN technique was used as alternative to assess the spore count. Clostridial spore counts of the 115 samples were very low. Only 9 samples $(7.8 \%)$ exceeded 50 spores/L. In milk samples from one supplier, the percentage of samples exceeding 50 spores/L (18.2\%) was significantly higher than in the samples of the other suppliers. 
Table 3. Clostridial spore counts in milk samples with and without silage feeding ${ }^{1}$

\begin{tabular}{|c|c|c|c|c|}
\hline \multirow[b]{2}{*}{ Spores/L } & \multicolumn{2}{|c|}{$\begin{array}{c}\text { Goat milk without } \\
\text { silage feeding }(\mathrm{n}=70)\end{array}$} & \multicolumn{2}{|c|}{$\begin{array}{l}\text { Goat milk with silage } \\
\text { feeding }(\mathrm{n}=144)\end{array}$} \\
\hline & No. & $\%$ & No. & $\%$ \\
\hline$<50$ & 53 & 75.7 & 58 & 40.3 \\
\hline 50 & 14 & 20.0 & 26 & 18.1 \\
\hline 100 & 1 & 1.4 & 12 & 8.3 \\
\hline$>100$ & 2 & 2.9 & 48 & 33.3 \\
\hline
\end{tabular}

${ }^{1} \mathrm{~A}$ spore count of $50 / \mathrm{L}$ equals 1 colony on the membrane filter $(20 \mathrm{~mL}$ of milk volume filtered).

\section{Distribution of Clostridial Species in Goat Milk}

Three hundred fifty-four colonies of putative sporeformers were isolated and analyzed by $16 \mathrm{~S}$ rRNA gene PCR. The results are shown in Table 4; 342 strains from 15 clostridial species were identified. The most common species were C. tyrobutyricum $(40.4 \%), C$. sporogenes $(38.3 \%)$, C. bifermentans $(7.6 \%)$, and $C$. perfringens $(5.3 \%)$.

Distinct differences in clostridial raw milk flora from suppliers using silage and nonsilage feeds were determined. The 2 most frequently occurring species $C$. tyrobutyricum and C. sporogenes accounted for $84.7 \%$ of the 288 isolates derived from samples of suppliers feeding silage. In contrast, in samples from suppliers without silage feeding, these species were detected in only $46.3 \%$ of the 54 isolates. Clostridium tyrobutyricum, as the most important species for late blowing, represented 45.5 and $13.0 \%$ of the Clostridium isolates originating from milk samples of suppliers using silage and nonsilage feeds, respectively. Out of 11 Paeniba- cillus strains, 10 were isolated from milk samples of suppliers without silage feeding.

Additionally, the potential for toxin production of $C$. perfringens $(\mathrm{n}=18)$ was analyzed. The results showed that the toxins type A (positive for $\alpha$-toxin) and type $\mathrm{D}$ (positive for $\alpha$ - and $\varepsilon$-toxin) were the most prevalent toxin genes. The $\alpha$-toxin gene was amplified in all $C$. perfringens isolates, whereas $\alpha$ - and $\varepsilon$-toxin genes were detected in only 8 isolates.

Differentiation between identical 16S rRNA gene amplified regions of $C$. sporogenes and $C$. botulinum was performed by multiplex PCR (De Medici et al., 2009). As none of these strains showed a potential for $C$. botulinum toxins, the isolates were classified as $C$. sporogenes.

\section{DISCUSSION}

\section{Adaptation of Filtration Procedure}

Reduction of sample volume from 40 to $20 \mathrm{~mL}$, prolongation of incubation time from 15 to $30 \mathrm{~min}$, and ul-

Table 4. Identification of anaerobic and facultatively anaerobic spore formers in goat milk isolates from modified reinforced clostridial agar (RCAm) and most probable number (MPN) tubes, using 16S rRNA gene analysis ${ }^{1}$

\begin{tabular}{llc}
\hline $\begin{array}{l}\text { No. of } \\
\text { clones }\end{array}$ & Closest hits in the GenBank database & $\begin{array}{c}\text { Sequence } \\
\text { similarity (\%) }\end{array}$ \\
\hline 138 & Clostridium tyrobutyricum (L08062) & 100 \\
64 & Clostridium sporogenes (AB558161) & 100 \\
67 & Clostridium sporogenes (GQ179698) & 99.8 \\
26 & Clostridium bifermentans (AM946379) & 100 \\
18 & Clostridium perfringens (AB588015) & 100 \\
10 & Clostridium sordellii (DQ978216) & 99.8 \\
5 & Clostridium tertium (Y18174) & 100 \\
4 & Clostridium thiosulfatireducens (EU937735), Clostridium sulfidigenes (EF199998) & 100 \\
3 & Clostridium cadaveris (AB542932) & 100 \\
2 & Clostridium butyricum (EU621841) & 100 \\
2 & Clostridium disporicum (NR_026491) & 100 \\
1 & Clostridium beijerinckii (CP000721) & 100 \\
1 & Clostridium paraputrificum (AB536771) & 100 \\
1 & Clostridium lituseburense (M59107) & 99.8 \\
5 & Paenibacillus barengoltzii (GQ284370) & 99.8 \\
5 & Paenibacillus macerans (AM406669) & 100 \\
1 & Paenibacillus sp. (HM212646) & 100 \\
1 & Bacillus sonorensis (JN998737) & \\
\hline
\end{tabular}

${ }^{1}$ Isolates originating from MPN tubes: Clostridium perfringens (6), Clostridium sporogenes (2), Clostridium tyrobutyricum (1), Clostridium beijerinckii (1), Clostridium sordellii (1), Clostridium cadaveris (1), and Bacillus sonorensis (1). 
trasonic treatment during incubation allowed filtration of goat milk even in the case of SCC exceeding $10^{6} /$ $\mathrm{mL}$. However, filterability was impaired in milk samples from goats in the last third of lactation. According to other proponents of the filtration approach, a similar effect on cow milk is not observable (J. Hummerjohann, Agroscope, personal communication). A pivotal difference between cow and goat milk is the SCC. We observed an average increase in the SCC from $8.7 \times 10^{5}$ in April to July $(\mathrm{n}=37)$ to $2.9 \times 10^{6}(\mathrm{n}=40)$ in December to March in the goat milk samples used for our study. It is known that milk SCC increases during the lactation period (Paape et al., 2001). Although we suspect an influence of the SCC on the filterability of goat milk, the observed elevated levels do not sufficiently explain the effect. Additional factors (e.g., cytoplasmic particles or changes in milk composition in late lactation) may also affect filterability of the milk.

\section{Validation of the MFT}

Productivity and Selectivity of the RCAm. Streaking reference cultures on RCAm showed that the target organism $C$. tyrobutyricum yielded by far the highest productivity of the tested clostridial strains. As expected, also C. butyricum, C. sporogenes, and C. perfringens were able to grow on this medium. Differences in $P_{R}$ in various assays might be explained by variable growth of strains and also by variable entry of oxygen during the test procedure.

Growth of clostridia other than C. tyrobutyricum was confirmed by the molecular species identification of clostridial flora (see below) where members of various clostridial species were isolated from the filters incubated on RCAm. Colony identification further demonstrated that the accompanying flora is sufficiently inhibited on RCAm, as only Paenibacillus spp. could be isolated on RCAm along with Clostridium spp. These results are in contrast to Jonsson (1990) who found no noticeable growth of 4 Paenibacillus polymyxa and 4 Paenibacillus macerans strains after 2 wk of anaerobic incubation on RCA containing D-cycloserine and neutral red. However, also the NIZO medium (milk-glucose medium adjusted to a $\mathrm{pH}$ of 5.45) is not selective for C. tyrobutyricum. In the current study, also C. perfringens, C. sporogenes, C. beijerinckii, Clostridium sordellii, Clostridium cadaveris, and Bacillus sonorensis were isolated from gas-positive MPN tubes.

That addition of acid fuchsin is helpful to differentiate C. tyrobutyricum colonies from other clostridial colonies (Bächli, 1997; Jakob, 2011) is not substantiated by our study. Also, Bergère and Sivelä (1990) expressed doubts that the staining of colonies by acid fuchsin is really specific to C. tyrobutyricum. To our observation, the color and shape of colonies on RCAm allows no reliable differentiation of grown colonies.

Comparison of the MFT and MPN Technique. Analysis of 47 milk samples revealed generally lower MFT than MPN counts. This is in accordance to the findings of Jakob (2011). He discussed the inferior productivity of MFT to be the effect of adding D-cycloserine to modified RCA, which should impair growth of bacilli but might impair growth of clostridia as well. Further factors were thought to be the shorter incubation time of MFT and the use of agar medium instead of liquid medium when applying MPN. In our experiments, all tested reference cultures except the $C$. tyrobutyricum strain showed growth on RCAm inferior to blood agar. Nevertheless, no evidence exists that the addition of D-cycloserine impairs productivity significantly, as all experiments were also carried out using RCA without D-cycloserine and both media yielded similar results (data not shown). In fact, differences might be explained by a more efficient resuscitation of the organisms in the MPN procedure due to the enrichment step in the liquid medium.

The differences in counts make it necessary to use method-specific limits for the assessment of raw milk quality. Agroscope, for instance, proposes a limit for farm bulk milk of suppliers not feeding silage of $25 \mathrm{BAB}$ spores per liter when using MFT (Jakob, 2011). When using modified Bryant and Burkey broth (MPN), this limit is set to 350 spores per liter.

\section{Spore Counts in Goat Farm Bulk Milk}

As expected, the clostridial load in milk samples from suppliers without using silage feed was significantly lower than in milk samples from suppliers using silage feeds. However, a noteworthy amount of milk samples from suppliers feeding silage $(40.3 \%)$ did not exceed the number of 50 spores per liter. This could explained by the sampling period (May to October), because in summer silage, feeding is less common due to the grazing period (Teuber, 1985; Dasgupta and Hull, 1989; Stadhouders and Spoelstra, 1990). Consequently, this seasonal variation was not observed in goat bulk milk samples of 5 suppliers not feeding silage. This implies that at farms not feeding silage, the spore levels are dependent on on-farm hygiene practices mainly associated with animal husbandry and cleanliness of teats. This was confirmed on the farm that revealed the largest number of milk samples exceeding 50 spores/L. Serious failures in hygiene measures were observed (wet and dirty open areas, soiled milking parlor, and pollution of drinking bowls with manure). 


\section{Effect of Feeding on the Population of Clostridia Species}

The most common clostridial species in goat bulk milk samples were $C$. tyrobutyricum and C. sporogenes, which is in accordance with the results of Bergère and Accolas (1986). Those authors found $75 \%$ of the isolates belonging to these 2 species in winter milk from cows. In our study, $84.7 \%$ of the isolates of milk samples from suppliers with silage feeding $(\mathrm{n}=288)$ belonged to these 2 species. However, in milk samples from suppliers without silage feeding $(\mathrm{n}=54)$, these 2 species accounted only for $46.3 \%$ of the total clostridial flora. In a Swedish study, Jonsson (1990) identified 75\% of the clostridial isolates in milk from silage-fed herds as C. tyrobutyricum; however, this was not proven in our study (prevalence of $C$. tyrobutyricum in milk from silage fed herds was $45.5 \%$ ). The mentioned prevalences are far from those observed in milk of goats fed a silagefree diet, as in these samples, only $13.0 \%$ of the clostridial isolates belonged to C. tyrobutyricum.

\section{CONCLUSIONS}

The MFT developed for counting BAB spores in cow milk was successfully adapted for goat milk. This technique is less laborious and time consuming than the MPN technique. However, when goats are in late lactation, filterability may be impaired even when using the modified sample preparation. Further, compared with the MPN technique, the MFT revealed BAB counts that were lowered by approximately $40 \%$. In addition, due to the reduction of sample volume, the limit of detection in goat milk was higher than in cow milk (50 vs. 25 spores/L, respectively). Because many samples from goats not fed silage were contaminated at spore levels lower than 50, the MFT was not capable of providing reliable quantitative results. Concerning milk samples from suppliers using silage feeds, higher spore levels are anticipated and milk with less than 1,000 BAB spores/L is deemed acceptable for delivery (Vissers et al., 2007; Jakob, 2011). In this case, precision of the results using the MFT is sufficient with respect to the $95 \%$ confidence limits of Poisson-distributed data.

\section{ACKNOWLEDGMENTS}

We thank Agroscope (Bern, Switzerland), especially Jörg Hummerjohann and Martina Frank for introduction to the membrane filtration technology and their hospitality during the stay at Liebefeld (Switzerland). We also thank Ernst Jakob (Agroscope, Bern, Switzerland) for his support. Special thanks to Dario De
Medici (Istituto Superiore di Sanità, Rome, Italy) for providing DNA as control for toxin gene PCR.

\section{REFERENCES}

Abgrall, B., and C. Bourgeois. 1985. Enumeration of Clostridium tyrobutyricum spores by membrane filtration and culture on gelose media. Lait 65:45-53.

AMA (Agrarmarkt Austria). 2013. Qualitätsuntersuchung der Rohmilch. Merkblatt der Agrarmarkt Austria. Accessed Jul. 31, 2014. http://www.ama.at/Portal.Node/public?gentics. $\mathrm{rm}=$ PCP \&gentics.pm = gti_full\&p.contentid $=10008.119132 \& 01$ Merkblatt_Qualitaet_Rohmilch.pdf.

Aureli, P., M. Di Cunto, A. Maffei, G. De Chiara, G. Franciosa, L. Accorinti, A. M. Gambardella, and D. Greco. 2000. An outbreak in Italy of botulism associated with a dessert made with mascarpone cream cheese. Eur. J. Epidemiol. 16:913-918.

Aureli, P., G. Franciosa, and M. Pourshaban. 1996. Foodborne botulism in Italy. Lancet 348:1594.

Bächli, M. 1997. Nachweis von Buttersäurebakterien-Sporen in Milch mittels Filtrationsmethode. MS Thesis. Diplomarbeit der philosophisch-naturwissenschaftlichen Fakultät. Universität Bern, Bern, Switzerland.

Bachmann, H.-P. 1995. Buttersäuregärung im Käse: Eine Literaturzusammenfassung. Agrarforschung 2:523-526.

Bachmann, H.-P., U. Bütikofer, M.-T. Fröhlich-Wyder, D. Isolini, and E. Jakob. 2011. Swiss-type cheeses. Pages 712-720 in Encyclopedia of Dairy Sciences. Vol. 1. J. W. Fuquay, P. F. Fox, and P. L. H. McSweeney, ed. 2nd ed. Academic Press, San Diego, CA.

Bergère, J. L., and J. P. Accolas. 1986. Non-sporing and sporing anaerobes in dairy products. Soc. Appl. Bacteriol. Symp. Ser. 13:373-396.

Bergère, J. L., and S. Sivelä. 1990. Detection and enumeration of clostridial spores related to cheese quality - Classical and new methods. IDF Bull. 251:15-23.

Bourgeois, C. M., O. Le Parc, B. Abgrall, and J.-J. Cleret. 1984. Membrane filtration of milk for counting spores of Clostridium tyrobutyricum. J. Dairy Sci. 67:2493-2499.

CEN (Comité Européen de Normalisation). 2011. Microbiology of food and animal feeding stuffs - Guidelines on preparation and production of culture media - Part 2: Practical guidelines on performance testing of culture media-Amendment 1: Test microorganisms for commonly used culture media. ISO/TS 11133-2:2003/ AMD 1:2011. European Committee for Standardization, Brussels, Belgium.

CNERNA (Centre National d'Études et de Recommandations sur la Nutrition et l'Alimentation). 1986. Recommandations pour l'estimation de la contamination du lait en spores de Clostridia par la méthode de culture en milieu liquide. Revue Laitière Française. 451:39-45.

Corpet, F. 1988. Multiple sequence alignment with hierarchical clustering. Nucleic Acids Res. 16:10881-10890.

Daly, D. F. M., P. L. H. McSweeney, and J. J. Sheehan. 2010. Split defect and secondary fermentation in Swiss-type cheeses-A review. Dairy Sci. Technol. 90:3-26.

Dasgupta, A. P., and R. R. Hull. 1989. Late blowing of Swiss cheese: Incidence of Clostridium tyrobutyricum in manufacturing milk. Aust. J. Dairy Technol. 44:82-87.

De Medici, D., F. Anniballi, G. M. Wyatt, M. Lindström, U. Messelhäußer, C. F. Aldus, E. Delibato, H. Korkeala, M. W. Peck, and L. Fenicia. 2009. Multiplex PCR for detection of botulinum neurotoxin-producing clostridia in clinical, food, and environmental samples. Appl. Environ. Microbiol. 75:6457-6461.

Freyer, T. F., and A. C. Halligan. 1976. The detection of Clostridium tyrobutyricum in milk. N.Z. J. Dairy Sci. Tech. 11:132.

Hüfner, J. 2001. Mikrobiologie-Schadkeime in Käse-Untersuchungen zum Verhalten von technologisch relevanten Schadkeimen in Käse am Beispiel von heterofermentativen Gasbildnern, Hefen, Clostridien und Coliformen-Teil 2. DZM Lebensmittelindustrie und Milchwirtschaft 122:444-452. 
Jakob, E. 2011. Analytik rund um die Buttersäuregärung. APL forum Nr. 85:1-23. Accessed Jul. 31, 2014. http://www.agroscope.ch/ publikationen/einzelpublikation/index.html?lang $=$ en\&aid $=26198$ \&pid $=26638$

Johnson, E. A., J. H. Nelson, and M. Johnson. 1990. Microbial safety of cheese made from heat-treated milk. Part II. Microbiology. J. Food Prot. 53:519-540.

Jonsson, A. 1990. Enumeration and confirmation of Clostridium tyrobutyricum in silages using neutral red, D-cycloserine, and lactate dehydrogenase activity. J. Dairy Sci. 73:719-725.

Klijn, N., F. F. Nieuwenhof, J. D. Hoolwerf, C. B. van der Waals, and A. H. Weerkamp. 1995. Identification of Clostridium tyrobutyricum as the causative agent of late blowing in cheese by species-specific PCR amplification. Appl. Environ. Microbiol. 61:2919-2924.

Le Bourhis, A.-G., J. Doré, J.-P. Carlier, J.-F. Chamba, M.-R. Popoff, and J.-L. Tholozan. 2007. Contribution of $C$. beijerinckii and $C$. sporogenes in association with $C$. tyrobutyricum to the butyric fermentation in Emmental type cheese. Int. J. Food Microbiol. 113:154-163.

Lycken, L., and E. Borch. 2006. Characterization of Clostridium spp. isolated from spoiled processed cheese products. J. Food Prot. 69:1887-1891.

NEN (Netherlands Normalisation Institute). 2009. NEN-ISO-6877: Milk and milk products - Detection of spores of butyric acid bacteria and determination of the content of spores of butyric acid bacteria by MPN technique. Vol. 6877. Netherlands Normalisation Institute, Delft, the Netherlands.

O'Mahony, M., E. Mitchell, R. J. Gilbert, D. N. Hutchinson, N. T. Begg, J. C. Rodhouse, and J. E. Morris. 1990. An outbreak of foodborne botulism associated with contaminated hazelnut yoghurt. Epidemiol. Infect. 104:389-395.

Paape, M. J., B. Poutrel, A. Contreras, J. C. Marco, and A. V. Capuco. 2001. Milk somatic cells and lactation in small ruminants. J. Dairy Sci. 84(Suppl.):E237-E244. http://dx.doi.org/10.3168/jds. S0022-0302(01)70223-8.

Pille, F. A. Martens, L. M. Schouls, L. Peelman, F. Gasthuys, C. S. Schot, C. De Baere, P. Desmet, and F. Vandenberghe. 2004. Detection of bacterial DNA in synovial fluid from horses with infectious synovitis. Res. Vet. Sci. 77:189-195.
Popoff, M. R., and B. R. Stiles. 2005. Clostridial toxins vs. other bacterial toxins. Pages 323-383 in Handbook on Clostridia. Vol. 1. P. Dürre, ed. Taylor \& Francis Group LLC, Boca Raton, FL.

Sébald, M., J. Jouglard, and G. Gilles. 1974. Botulisme humain de type $\mathrm{B}$ après ingestion de fromage. Ann. Microbiol. (Paris) 125A:349-357.

Sheehan, J. J. 2011. Cheese: Avoidance of gas blowing. Pages 661-666 in Encyclopedia of Dairy Sciences. Vol. 1. 2nd ed. J. W. Fuquay, P. F. Fox, and P. L. H. McSweeney, ed. Academic Press, San Diego, $\mathrm{CA}$

Stadhouders, J. G. Hup, and F. F. J. Nieuwenhof, 1985. Silage and cheese quality. Netherlands Institute for Dairy Research (NIZO) Mededeling M19A:1-40. NIZO, Ede, the Netherlands.

Stadhouders, J., and S. F. Spoelstra. 1990. Prevention of contamination of raw milk by making a good silage. IDF Bull. 251:24-31.

Teuber, M. 1985. Das Nitratproblem bei der Käseherstellung - Gegenwärtiger Stand der Gegenmaßnahmen. Molkerei-Zeitung Welt der Milch 39:937-940.

van den Berg, G., C. B. G. Daamen, E. de Vries, W. van Ginkel, and J. Stadhouders. 1988. Test of bacteria-removing separators, manufactured by Westfalia Separator AG, for the manufacture of Gouda cheese. NIZO Rapport No. R127:23-24.

VDLUFA (Verband Deutscher Landwirtschaftlicher Untersuchungsund Forschungsanstalten). 1996. Bestimmung von käsereischädlichen Clostridien-Verfahren mit pH-modifiziertem RCM-Agar. Methodenbuch, Band VI. VDLUFA M.7.18.3.1. VDLUFA-Verlag Darmstadt, Germany.

Vissers, M. M. M., F. Driehuis, M. C. Te Giffel, P. De Jong, and J. M. C. Lankveld. 2007. Concentration of butyric acid bacteria spores in silage and relationships with aerobic deterioration. J. Dairy Sci. 90:928-936.

Yoo, H. S., S. U. Lee, K. Y. Park, and Y. H. Park. 1997. Molecular typing and epidemiological survey of prevalence of Clostridium perfringens types by multiplex PCR. J. Clin. Microbiol. 35:228-232.

Zangerl, P. 1989. Aspekte der Clostridienproblematik und AnaerobierZüchtung. Milchwirtschaftliche Berichte 101:223-228. 